\title{
Preparation of Microcapsules Containing Artificial Diet for Tropical Fishes with Spray Gelling Method
}

\author{
Yoshinari Taguchi, Takanori Suzuki, Natsukaze Saito, Masato Tanaka* \\ Graduate School of Science and Technology, Niigata University, Niigata, Japan \\ Email: ^tanaka@eng.niigata-u.ac.jp
}

How to cite this paper: Taguchi, Y., Suzuki, T., Saito, N. and Tanaka, M. (2017) Preparation of Microcapsules Containing Artificial Diet for Tropical Fishes with Spray Gelling Method. Journal of Encapsulation and Adsorption Sciences, 7, 1-9. https://doi.org/10.4236/jeas.2017.71001

Received: December 12, 2016

Accepted: February 3, 2017

Published: February 6, 2017

Copyright (c) 2017 by authors and Scientific Research Publishing Inc. This work is licensed under the Creative Commons Attribution International License (CC BY 4.0).

http://creativecommons.org/licenses/by/4.0/

\begin{abstract}
The microcapsules containing the artificial diet for tropical fishes were prepared with the spray gelling method in order to prevent water environmental pollution. The carboxymethyl cellulose sodium aqueous solution, in which $\alpha$-tocopherol droplets containing the powdery artificial diet were dispersed, was dropped or sprayed into the chitosan aqueous solution. Microcapsules were prepared by forming polyionic complex shell made from chitosan and carboxymethyl cellulose sodium. In the experiment, the concentration of carboxymethyl cellulose sodium ( $\mathrm{CMCNa}$ ) was mainly changed to investigate the effect on the diameters of microcapsules, the content and the microencapsulation efficiency. The microcapsules couldn't be prepared with the concentration of carboxymethyl cellulose sodium less than $3.0 \mathrm{wt} \%$. The microcapsules were the core-shell type. The diameters of microcapsules were increased with the concentration of $\mathrm{CMCNa}$ and the microencapsulation efficiency of ca. $100 \%$ could be obtained by the preparation method presented in this study. The microcapsules were found to be eaten well by tropical fishes and to prevent water environmental pollution.
\end{abstract}

\section{Keywords}

Microencapsulated Diets, Spray Gelling Method, Heterocoagulation, Artificial Diet, Carboxymethyl Cellulose Sodium

\section{Introduction}

Many kinds of microcapsules with the principal functions as the protection and the controlled release of core materials have been developed and applied in the various fields [1] [2] [3].

As an interesting example of application of microcapsules, it has been tried to 
microencapsulate a lot of nutritious compositions for cultivating various fishes [4] [5] [6] [7].

The main purpose of these microcapsules was to microencapsulate a few balanced nutritious baits in accordance with the conditions of fishes [8] [9] [10].

Nowadays, many kinds of microencapsulated diets for fishes have been developed and applied properly according to the growth degree of fishes such as both larval and adults stages of development.

A. Luzardo et al. [11] have reviewed about microencapsulation of diets and vaccines for cultured fishes, crustaceans and bivalve mollusks. And they have reported the main advances due to the application of microencapsulation techniques and microencapsulation of nutrition and vaccination.

Yufera et al. have developed the highly efficient microencapsulated food for rearing early larvae of marine fishes [12].

They have prepared the microcapsules containing diets composed of casin, fish protein hydrolysate, vitamin mixture and etc. by using interfacial polymerization of the dietary protein. And they have reported the effect of microencapsulated food on the growth rate of fish.

Furthermore, they have prepared the microcapsules with the protein shell and investigated the effect of a kind of microdiets on leaching of free amino acid [13].

Besides these works, the many works have described mainly how to prepare the microcapsules containing the various microdiets and how to evaluate the effect of microencapsulated diets on the growth rate of fishes [7] [8] [9].

However, there are few works describing the effect of microencapsulation of artificial food on the prevention of water environmental pollution [13].

Hereafter, it will become important more and more to develop the preparation method of microencapsulated diets to be able to achieve the effective contribution to both the growth rate of fishes and the prevention of water environmental pollution.

In this study, the effect of microencapsulated diets on the prevention of water environmental pollution was mainly estimated, because the effective contribution of microencapsulated diets to the growth rate of fishes may be sufficiently estimated by adjusting the nutritional compositions.

The purposes of this study are to try to prepare the microcapsules containing the artificial diet for tropical fishes with the spray gelling method and to characterize the effect of the microencapsulation of diets on the prevention of water environmental pollution.

\section{Experiment}

\subsection{Materials}

Materials used to prepare the microcapsules containing the artificial diet were as follows.

Carboxymethyl cellulose sodium (CMCNa) and chitosan were used to form the microcapsule shell. $\alpha$-tocopherol (VE) was used as the binder for the pow- 
dery core material. Ambrose of artificial diet for tropical fishes was used as the core material, which was composed of chitin and various proteins.

Soybean lecithin (SBL) was used as an oil soluble surfactant.

Acetic acid (AC) was used to dissolve chitosan in water.

Ambrose was from Aqua Service Co., Ltd, Tokyo, Japan and the others were from Wako Chemical Co., Ltd., Tokyo, Japan.

\subsection{Preparation of Microcapsules}

In order to investigate whether the desired microcapsules could be prepared with the experimental conditions adopted in this study or not, it was tried first to prepare the microcapsules with the dropping method and then, with the spray gelling method.

Figure 1 and Figure 2 show the flow chart and the schematic diagram of experimental apparatus for preparing the microcapsules, respectively.

The $(\mathrm{S} / \mathrm{O})$ dispersion composed of VE, SBL and Ambrose was prepared and added into the CMCNa aqueous solution to form the $(\mathrm{S} / \mathrm{O}) \mathrm{W}$ dispersion. The $(\mathrm{S} / \mathrm{O}) \mathrm{W}$ dispersion was dropped or sprayed into the chitosan aqueous solution through the nozzle with the diameter of $1.2 \mathrm{~mm}$ as shows in Figure 2.

Table 1 shows the experimental conditions adopted in this study.

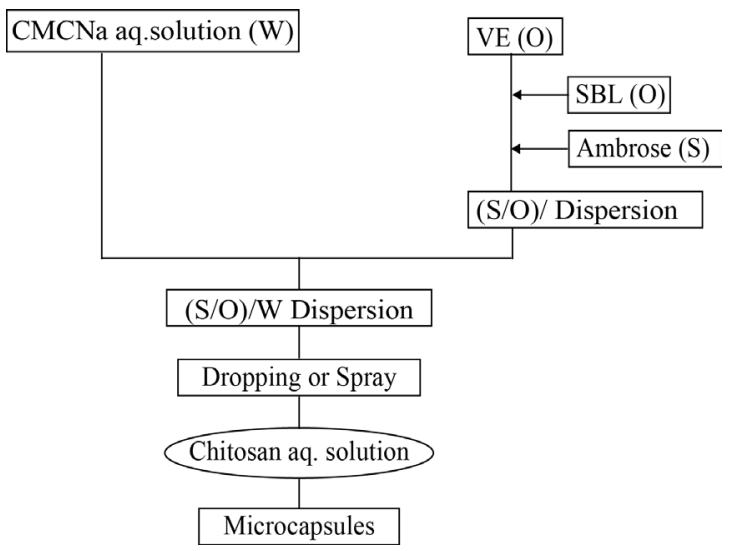

Figure 1. Flow chart for preparing microcapsules.

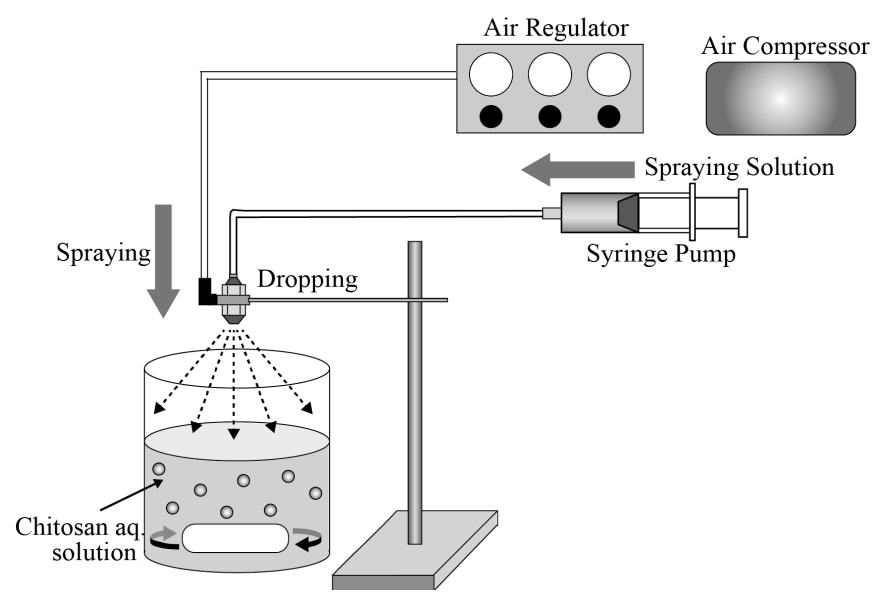

Figure 2. Schematic diagram of experimental apparatus. 
Table 1. Experimental conditions.

\begin{tabular}{cc}
\hline <Spraying Solution> & \\
\hline Ambrose (Core Material) & $5.0 \mathrm{~g}$ \\
CMCNa aq. Solution & $50 \mathrm{~g}$ \\
Concentration & $\mathrm{C}_{\mathrm{CM}}=1.0 \mathrm{wt} \% \sim 9.0 \mathrm{wt} \%$ \\
VE (binder) & $2.0 \mathrm{~g}$ \\
SBL & $0.2 \mathrm{~g}$ \\
\hline$<$ Hardening Solution> & \\
\hline $2.0 \mathrm{wt} \%$ Chitosan Acetic Acid aq. Solution & $200 \mathrm{~g}$ \\
\hline$<$ Dropping/Spraying $>$ & $2.0 \mathrm{~mm}$ \\
\hline Nozzle Diameter & $0.2 \mathrm{MPa}$ \\
Spraying Pressure & $150 \mathrm{ml} / \mathrm{h}$ \\
\hline Solution Feeding Speed & \\
\hline
\end{tabular}

\subsection{Characterization}

\subsubsection{Observation}

The whole, the surface and the inner structure of the microcapsules prepared were observed with optical microscope (DP10, Olympus Co., Ltd., Tokyo, Japan) and stereo microscope (SE1145TR: Olympus Co., Ltd., Tokyo, Japan).

\subsubsection{Diameter Distributions and Mean Diameters}

The diameter distributions and mean diameters of microcapsules were measured with the particle size analyzer (SALD-3000, Shimazu Seisakusho Ind., Co., Kyoto, Japan).

\subsubsection{Analysis of Microcapsule Surface}

The surface of microcapsule was analyzed with FTIR (FTIR-8200PC, Shimazu Seisakusho, Ind., Co., Kyoto, Japan) in order to investigate the formation mechanism of polyionic complex shell.

\subsubsection{Measurement of Turbidity of Water}

The degree of water environmental pollution due to artificial diet and the microcapsules was measured with the Ultra-violet spectrophotometer (UV-160A, Shimazu Seisakusho Ind., Co., Tokyo, Japan) and the pH meter (F-55, Horiba Seisakusho Co., Ltd., Tokyo, Japan).

These measurements are based on that the higher the degree of water environmental pollution becomes, the higher the turbidity and the $\mathrm{pH}$ value of water become.

\subsubsection{Observation of Eating Microcapsules by Tropical Fishes}

Tropical fishes used in this study were zebrafishes.

The microcapsules of a given weight were added into the water tank where many zebrafishes lived.

It was directly observed whether zebrafishes ate the microcapsules or not. 


\section{Results and Discussion}

\subsection{Preliminary Preparation with Dropping Method}

Figure 3 shows the optical microscopic photographs of microcapsules prepared with the dropping method in order to investigate whether the microcapsules could be prepared with the experimental conditions or not.

From Figure 3, it was confirmed that the microcapsules could be prepared with the experimental conditions used in this study.

Concretely, the microcapsules without the core (Figure 3(a)) and with VE and SBL (Figure 3(b)) were found to be spherical and the microcapsules with VE, SBL and Ambrose (Figure 3(c)) became slightly rough because of containing powdery core material.

Also, the core composed of Ambrose, SBL and VE was found to be microencapsulated well (Figure 3(d)) and the microcapsules became the core-shell type.

\subsection{Preparation with Spray Gelling Method}

As the microcapsules could be prepared with the compositions adopted in this study, it was tried to prepare the microcapsules with the spray gelling method.

Figure 4 shows the photographs of microcapsules observed by the stereo microscope (Figure 4(a), Figure 4(b)) and the optical microscope (Figure 4(c), Figure 4(d)). From these results, the irregular microcapsules with the wider diameter distribution could be prepared even with the spray gelling method.

As the diameters of aqueous solution droplets sprayed were largely changed by the physical properties of aqueous solutions (especially the viscosity) [14], the microcapsules were prepared by changing the concentration of $\mathrm{CMCNa}$.

Figure 5 shows the dependences of the viscosity of $\mathrm{CMCNa}$ aqueous solution and the mean diameters of microcapsules on the concentration $\left(\mathrm{C}_{\mathrm{CM}}\right)$ of $\mathrm{CMCNa}$ aqueous solution.

The microcapsules couldn't be prepared with the lower concentration of carboxymethyl cellulose sodium than $3.0 \%$.

(a)

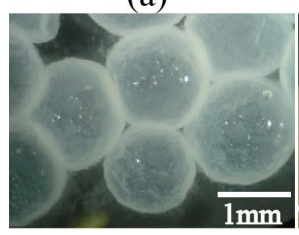

(b)

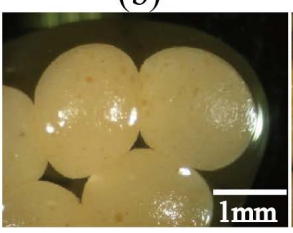

(c)

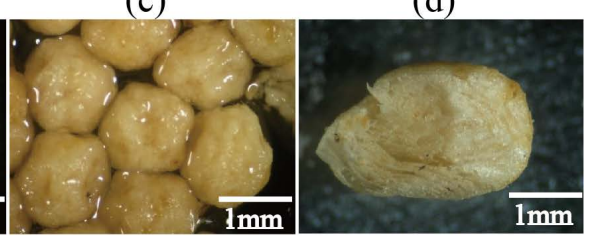

Figure 3. Photographs of microcapsules prepared with dropping method $\left(\mathrm{C}_{\mathrm{CM}}=6 \mathrm{wt} \%\right)$.

(a)

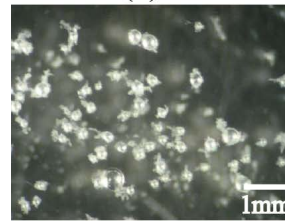

(b)

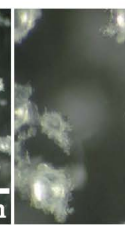

(c)

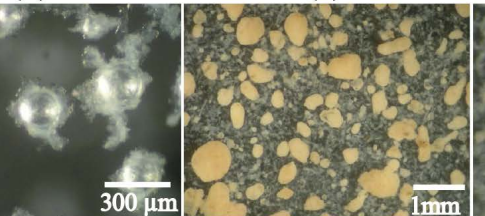

(d)

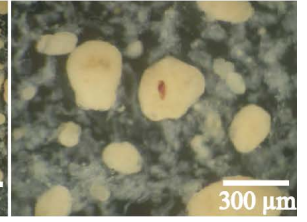

Figure 4. Photographs of microcapsules prepared with spray gelling method $\left(\mathrm{C}_{\mathrm{CM}}=6\right.$ wt\%). 


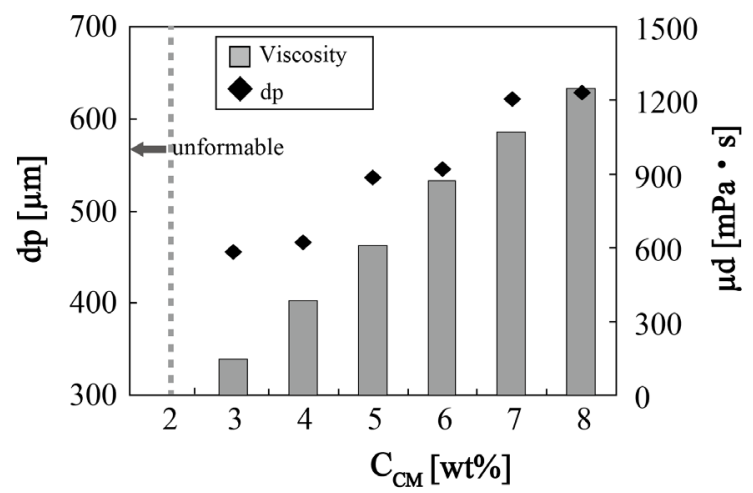

Figure 5. Dependences of Microcapsule Diameter and Viscosity of CMCNa Aqueous Solution on Concentration of CMCNa.

However, the mean diameters (dp) changed from $\mathrm{dp}=450 \mu \mathrm{m}$ at $\mathrm{C}=3.0 \mathrm{wt} \%$ $(\mu \mathrm{d}=250 \mathrm{mpa} \cdot \mathrm{s})$ to $\mathrm{dp}=620 \mu \mathrm{m}$ at $\mathrm{C}=8.0 \mathrm{wt} \%(\mu \mathrm{d}=1250 \mathrm{mpa} \cdot \mathrm{s})$.

\subsection{Analysis of Microcapsule Surface}

In order to analyze the chemical composition on the surface of microcapsule, the result of FTIR analysis was shown in Figure 6, where chitosan and the microcapsules prepared with $\mathrm{C}_{\mathrm{CM}}=6.0 \mathrm{wt} \%$ were analyzed, respectively.

As the absorption peaks at $\lambda=1500 \mathrm{~cm}^{-1}$ and $\lambda=3400 \mathrm{~cm}^{-1}$ were due to $\mathrm{NH}_{2}$ of chitosan, the microcapsules were found to be formed with the polyionic complex between chitosan and CMCNa.

\subsection{Microencapsulation Mechanism}

From the results obtained above, the microencapsulation mechanism could be derived as shown in Figure 7.

Namely, the CMCNa aqueous solution containing Ambrose coated with VE and SBL was dropped or sprayed into the chitosan aqueous solution.

Then, the anionic $\mathrm{CMCNa}$ dissolved in water must react with the cationic chitosan to form the microcapsule shell of polyionic complex.

As a result, powdery Ambrose coated with VE and SBL was stably microencapsulated with the polyionic complex shell.

\subsection{Effect of Microencapsulation on Water Environmental Pollution}

As it was expected that water environmental pollution could be prevented by the microencapsulation of Ambrose, the effect of microencapsulation was estimated by measuring the turbidity and the $\mathrm{pH}$ value in the water tank.

Figure 8 shows the absorbance for water dispersing the microcapsules prepared at each concentration of $\mathrm{CMCNa}$ together with the result for water dispersing only Ambrose.

The absorbance for water dispersing only Ambrose was ca. 0.2, however, the absorbance for water dispersing each microcapsule was smaller than 0.03 .

Figure 9 shows the change of the $\mathrm{pH}$ values for water for dispersing each mi- 


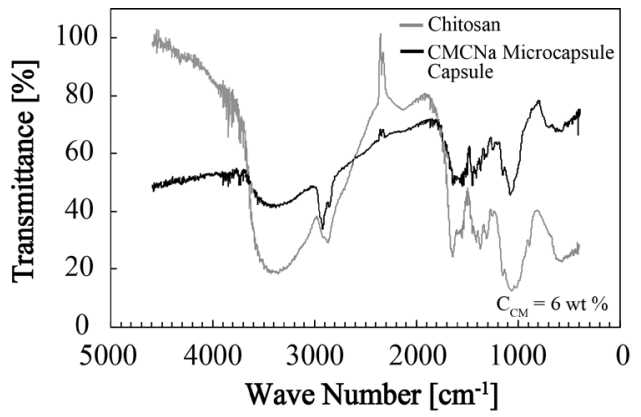

Figure 6. FTIR analysis of microcapsule.
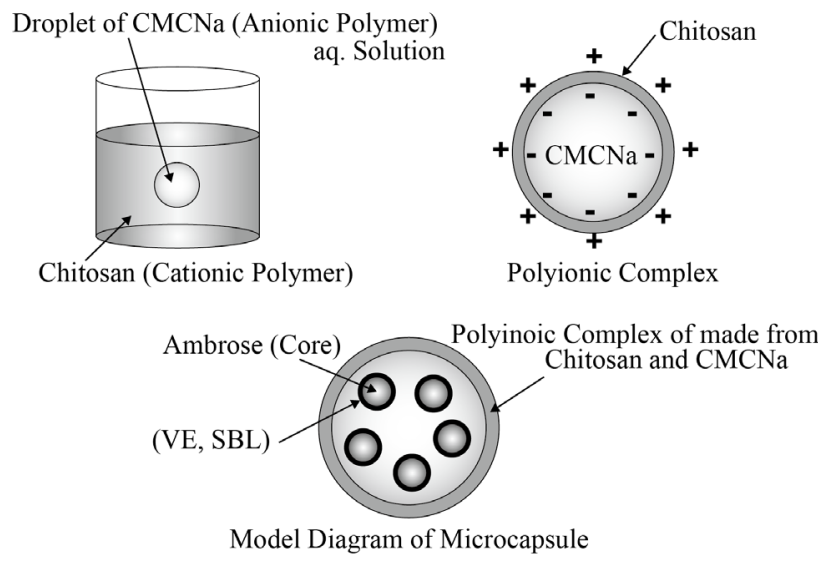

Figure 7. Formation mechanism of microcapsule.

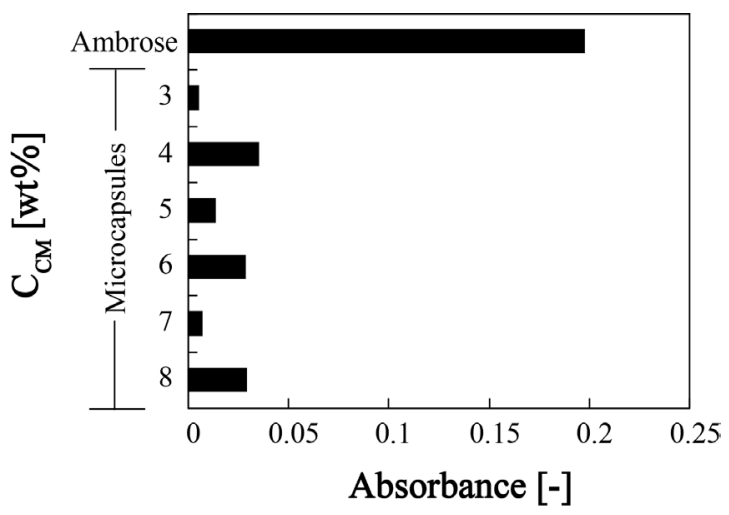

Figure 8. Absorbance for water dispersing Ambrose and microcapsules.

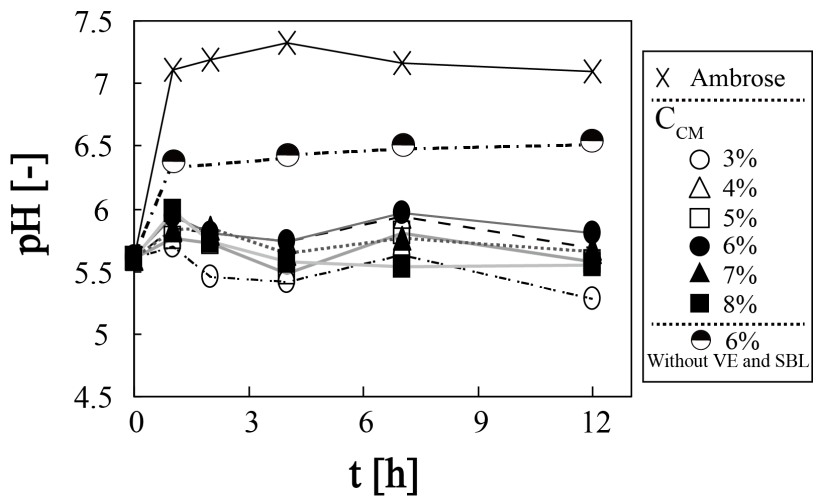

Figure 9. Change of the $\mathrm{pH}$ value for water dispersing microcapsule and Ambrose. 
crocapsule and only Ambrose.

In the case of dispersing only Ambrose, the $\mathrm{pH}$ value abruptly increased from $\mathrm{pH}=5.5$ to $\mathrm{pH}=7.2$ after ca. $1 \mathrm{~h}$.

However, the $\mathrm{pH}$ value of water dispersing each microcapsule was kept almost constant (ca. $\mathrm{pH}=5.5$ ).

For comparison, the change of the $\mathrm{pH}$ value for the microcapsules prepared without VE and SBL was shown in Figure 9, too. The $\mathrm{pH}$ value increased from $\mathrm{pH}=5.5$ to $\mathrm{pH}=6.5$ after ca. $1 \mathrm{~h}$. This result may be due to the fact that powdery Ambrose was easy to dissolve out of the microcapsule because of lack of protection effect due to VE and SBL.

From these results, it was confirmed that water environmental pollution could be satisfactorily prevented by microencapsulating Ambrose with the double shells composed of VE, SBL and polyionic complex.

Also, it was estimated that ca. $100 \%$ of microencapsulation efficiency could be obtained, because the turbidity and the $\mathrm{pH}$ value were kept constant for $12 \mathrm{~h}$.

\subsection{Observation of Eating Microcapsules by Tropical Fishes}

It was directly observed whether the microcapsules were eaten by tropical fishes or not.

As a result, it was found that the microcapsules were actively eaten by tropical fishes.

Furthermore, it will be expected that chitosan, VE and SBL could contribute to the growth rate of tropical fishes in addition to the prevention of water environmental pollution.

\section{Conclusions}

It was tried to prepare the microcapsules containing the artificial diet for tropical fishes with the dropping method and the spray gelling method.

The following results were obtained.

1) The microcapsule shell was formed by the polyionic complex made from carboxymethyl cellulose sodium and chitosan.

2) The microcapsules were the core shell type.

3) The microcapsules couldn't be prepared with the concentration of carboxymethyl cellulose sodium less than $3.0 \mathrm{wt} \%$.

4) The diameters of microcapsules could be changed from $450 \mu \mathrm{m}$ to $620 \mu \mathrm{m}$ according to the concentration of the carboxymethyl cellulose sodium aqueous solution.

5) Water environmental pollution could be prevented by microencapsulating Ambrose with the double shells composed of $\alpha$-tocopherol, lecithin and the polyionic complex.

6) The microcapsules were actively eaten by tropical fishes.

\section{References}

[1] Tanaka, M. (2008) Kay Point of Preparation of Nano/Microcapsules. Techno Sys- 
tem Publishing Co. Ltd., Tokyo.

[2] Kondo, T. (1967) Saishin Maikrokapuseruka Gijutsu (Microencapsulation Technique). TES, Tokyo.

[3] Koishi, M., Eto, K. and Higure, H. (2005) (Preparation + Utilization) Microcapsules. Kogyo Chosakai, Tokyo.

[4] Castro, D.R., Roman, S.P. and Brintrup, G.E. (2014) Microencapsulated Food Composition for Fish Larvae and Method for Obtaining Same by Spray Drying. EP2786663 A1.

[5] Chi, F., Wen, Q.T., Lu, T.S. and Kong, H. (2008) Feed for Fish and Use Thereof. US 2008/0276877 A1.

[6] Hatate, Y. and Kawano, Y. (1998) Microcapsule for Feed. JP1998/10-327770.

[7] Tesser, M.B. and Portella, M.C. (2003) Degradation Analysis of Microencapsulated Diet in Pacu (Piaractus mesopotamicus Holmberg, 1887) Larvae Intestine through Scanning Electron Microscopy (SEM). Maringá, 25, 49-52.

[8] Tan, X.-L., Zhao, J., Wang, S. and Zhang, F. (2015) Optimization and Evaluation of Microencapsulated Artificial Diet for Mass Rearing the Predator Ladybird, Propylea japonica (Coleoptera: Coccinellidae). Insect Science, 22, 111-120. https://doi.org/10.1111/1744-7917.12098

[9] Rice, M.A., Bengston, D.A. and Jaworski, C. (1994) Evaluation of Artificial Diets for Cultured Fish. NRAC Fact Sheet, No. 222.

[10] Jonse, D.A., Kanazawa, A. and Ono, K. (1979) Studies on the Nutritional Requirements of the Larval Stage of Penaeus japonicas Using Microencapsulated Diets. Marine Biology, 54, 261-267. https://doi.org/10.1007/BF00395788

[11] Luzardo-Alvarez, A., Otero-Espinar, F.J. and Blanco-Méndez, J. (2010) Microencapsulation of Diets and Vaccines for Cultured Fishes, Crustaceans and Bibalve Mollusks. Journal of Dray Delivery Science and Technology, 20, 277-288. https://doi.org/10.1016/S1773-2247(10)50045-5

[12] Yúfera, M., Kolkovki, S., Fernández-Díaz, C. and Dabrowaki, K. (2002) Free Amino Acid Leaching from a Protein-Walled Microencapsulated Diet for Fish Larvae. $A q$ uaculture, 214, 273-387. https://doi.org/10.1016/S0044-8486(01)00902-4

[13] Yúfera, M., Pasual, E. and Fernández-Díaz, C. (1994) A Highly Efficient Microencapsulated Food for Rearing Early Larvae of Marine Fish. Aquaculture, 177, 249 256. https://doi.org/10.1016/S0044-8486(99)00088-5

[14] Shirokawa, K., Taguchi, Y., Yokoyama, H., Ono, F. and Tanaka, M. (2013) Preparation of Temperature and Water Responsive Microcapsules Containing Hydroquinone with Spray Drying Method. Journal of Cosmetics, Dermatological Sciences and Applications, 3, 49-54. https://doi.org/10.4236/jcdsa.2013.33A2012 
Submit or recommend next manuscript to SCIRP and we will provide best service for you:

Accepting pre-submission inquiries through Email, Facebook, LinkedIn, Twitter, etc. A wide selection of journals (inclusive of 9 subjects, more than 200 journals)

Providing 24-hour high-quality service

User-friendly online submission system

Fair and swift peer-review system

Efficient typesetting and proofreading procedure

Display of the result of downloads and visits, as well as the number of cited articles Maximum dissemination of your research work

Submit your manuscript at: http://papersubmission.scirp.org/

Or contact jeas@scirp.org 